\section{Tim Cain}

is the head of research and insight at The UK Association of Online Publishers (AOP), the industry body representing online publishing companies that create original, branded and quality content. AOP champions the interests of companies from newspaper and magazine publishing, TV and radio broadcasting and pure online media. The AOP raises awareness and addresses concerns relating to all areas of online publishing to industry and Government, covering topics such as paidfor-content, online subscription models, data protection, copyright, content management, new technologies and audience measurement. AOP publishes original research including the annual Census. It also hosts forums, conferences and events where members can debate issues, meet peers and network.

Keywords: mobile, data, tablet, smartphone, publishers, revenue

\section{Data strategy a major priority}

Tim Cain

Association of Online Publishers Queens House, 55/56 Lincoln's Inn Fields, London, WC2A $3 \mathrm{LJ}$

E-mail: Tim.cain@ukaop.org.uk

\section{Business Intelligence}

\section{UK publishers facing digital challenges}

\author{
Tim Cain
}

Received: 14th December 2012

\begin{abstract}
The Association of Online Publishers Content and Trends Census highlights the growing importance of mobile internet for publishers; as audiences increasingly access websites via mobile devices, one of the biggest challenges for publishers becomes monetising that channel.
\end{abstract} Journal of Direct, Data and Digital Marketing Practice (2013) 14, 244-248. doi:10.1057/dddmp.2012.40

\section{Background and methodology}

The Association of Online Publishers (AOP) Census, currently in its tenth year, is an annual survey of AOP members' businesses to provide an insight into the digital publishing industry and to provide a benchmark for members. This is the fourth year that the Census has been split into a 'Content and Trends' survey published in the autumn, and an 'Organisation' survey published in the spring.

The Census acts as a temperature check of the digital publishing landscape by reflecting the level of current activities being undertaken, the expected degrees of change over the next 12 months and capturing sentiment around the issues of most prominence, either as an opportunity or as a threat.

The AOP Content \& Trends Census (survey, fieldwork and analysis) was conducted in July/August 2012.

\section{Key themes}

Mobile might be making the headlines from this year's Content and Trends Census, but publishers believe that there is a greater diversity of key trends to occupy their thinking over the next 12 months than we have previously seen. There is a fairly even spread across five potential trends - on the mobile front, smartphone-optimized sites and applications and the development of the iPad and other tablets as a platform for digital editions and apps are both equally acknowledged as the biggest trend (by 18 per cent of publishers). But so too is data management and ownership (Figure 1). 
Mobile becoming more important than website

\section{Advertisers out of step with publishers}

\section{Ad revenues not migrating to mobile}

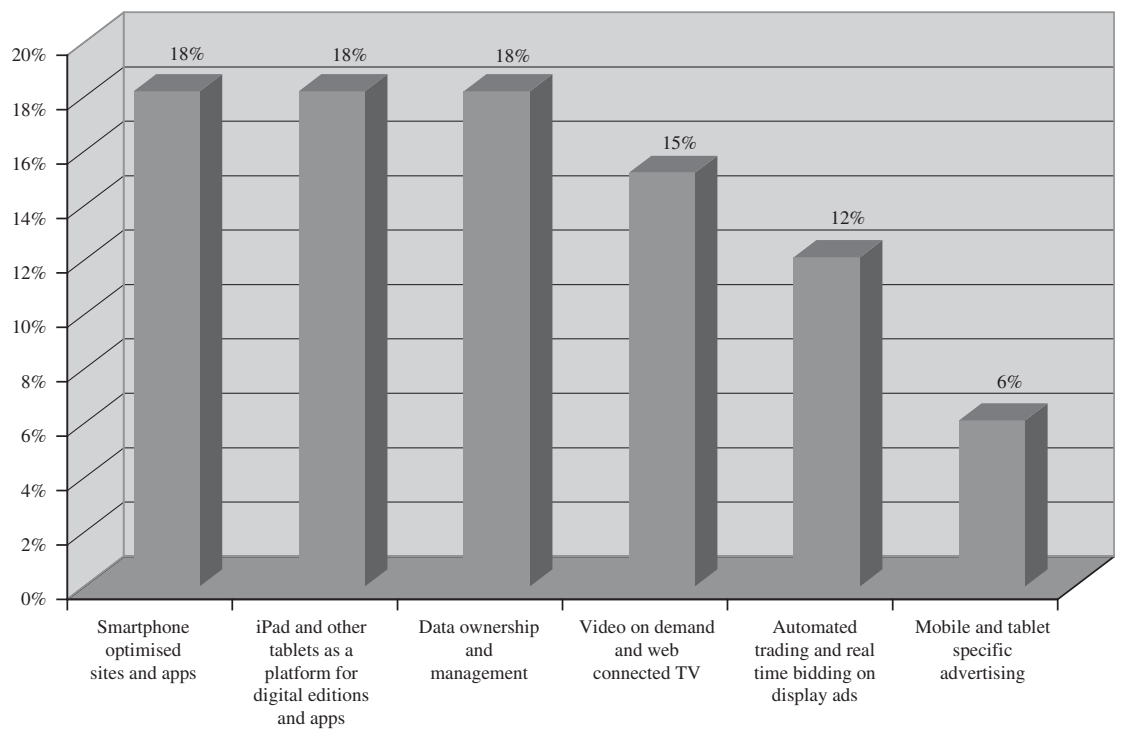

Figure 1: Smartphones, tablets and data all challenge publishers

Just behind these, there are video on demand and web connected TV (15 per cent) and automated trading and real time bidding on display ads (12 per cent). Both of these trends have grown significantly year-on-year, as has the focus on data, which has seen a threefold increase from those who thought it would be a key trend a year ago. In fact, now, nearly seven out of 10 publishers say a long-term data strategy will become the most significant priority to develop their commercial assets.

\section{Emphasis on mobile}

As past Census surveys have shown, the emphasis on the growth of Mobile devices as a digital publishing opportunity continues to occupy a position of priority in the publisher's plans. In terms of opportunities, almost all publishers (90 per cent) believe that iPad/tablets offer the most significant one over the next 12 months, whereas generally mobile internet, specifically applications and mobile ads, all feature in the top five perceived opportunities for the coming year. Looking ahead, three quarters of publishers believe that mobile devices will become more important than traditional sites.

Publishers are continuing to adapt their sites for increasing mobile consumption by audiences, and now over 60 per cent state that the majority of sites in their portfolios are optimized for mobile compared with around 50 per cent who would have said that a year ago. That compares with only 40 per cent of the top 100 advertisers who have mobile-optimized sites, which in itself is an inhibitor to the growth of mobile advertising — returning the consumer to a non-mobile-friendly site experience has to be an ineffective use of advertising.

The top three priorities of focus on content delivery over the next 12 months are all in the mobile area - mobile internet, smartphone 


\section{Concerns about audience size}

\section{UK leads Europe on mobile traffic}

\section{Mobile revenues to double}

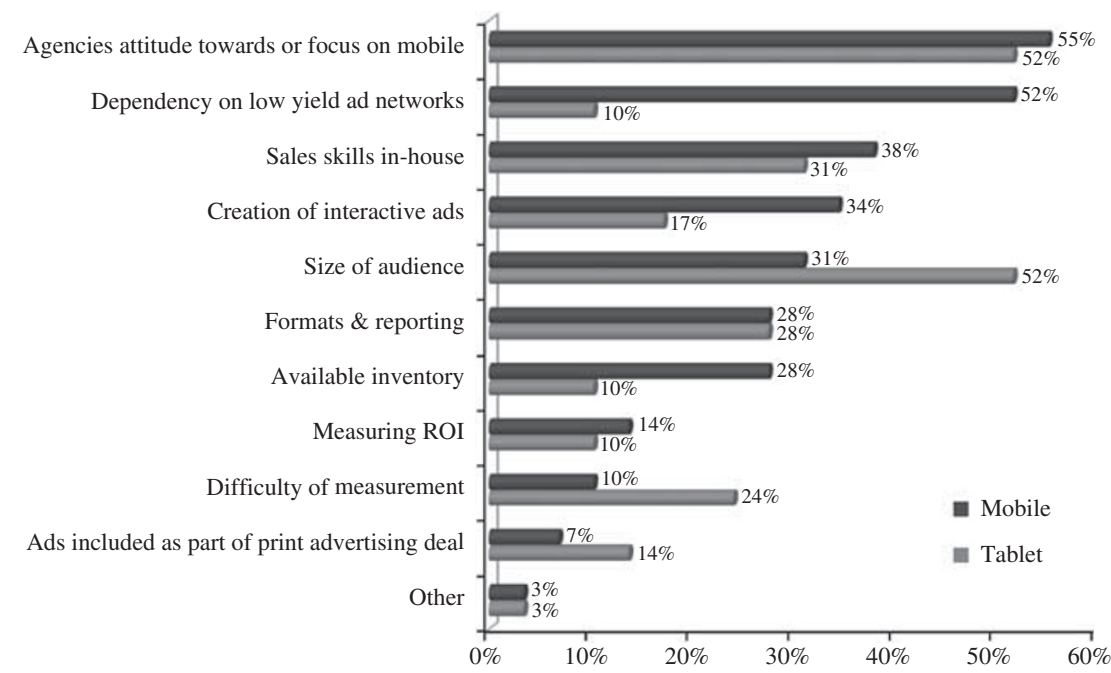

Figure 2: Agencies' attitudes are inhibiting growth

and tablet applications - all acknowledged by one in two publishers. However, although more people than ever are consuming content on their smartphones and tablets, ad revenues are not migrating to those devices at the same rate. According to the Census, publishers rank ad agency attitude as the greatest inhibitor to revenue growth for the mobile model (see Figure 2). Priorities for monetization are led by maximizing the ad yield via direct sales (57 per cent) and growing paid content/subscriptions (40 per cent).

Nearly twice as many respondents to the Census said that agency attitude, rather than audience size, would hold back mobile revenue growth next year, as cited by 55 and 31 per cent, respectively. Dependency on low-yield ad networks would also hamper growth, according to 52 per cent. For tablets, the two biggest inhibitors to growth will be ad agencies' dependency on low-yield ad networks and size of audience, both on 52 per cent.

Mobile still has a long way to go to fulfil its revenue potential. Figures from Comscore showed that in June, over 16 per cent of the UK's online traffic came from mobile devices (phones, tablets and consoles) - the highest rate of mobile traffic in Europe and, by quite some way, with Ireland next at 11.5 per cent and Russia third with just over 10 per cent. The Content and Trends Census has found that 87 per cent of publishers get at least 10 per cent of their digital traffic from mobile users. In fact, a third get over 20 per cent of their traffic from mobile. Contrast this with mobile revenues as a percentage of digital revenues where only 29 per cent generate over 5 per cent of their revenues from this traffic.

\section{Changes to the mobile ad market}

We are going to see some fundamental changes to the mobile ad market over the coming year, as ad agency attitudes catch up with publisher investment and mobile audience size. These changes include: 


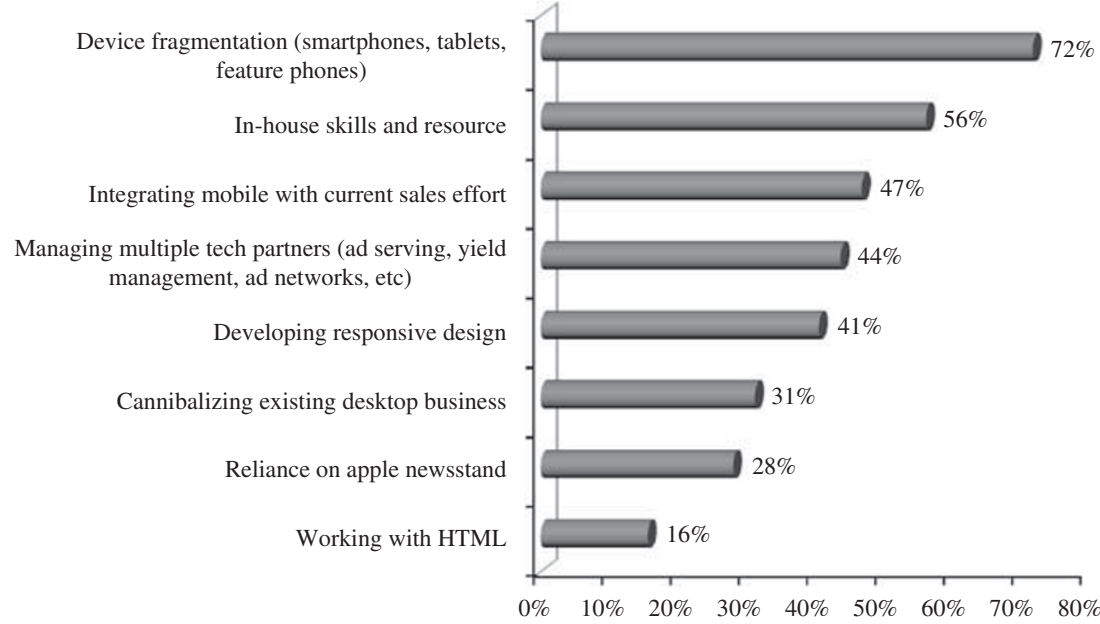

Figure 3: Business model for applications diverging by device

- Ad revenues will experience massive growth, doubling within 12 months of agencies, recognizing the opportunity in the mobile market.

- Publishers will stop creating content according to platform and will increasingly use technology that automatically adapts content to format to distribute it as widely as possible. One CMS will 'disseminate' to all platforms, which will allow publishers to align content and pricing strategies.

- Audiences will accept that they can only receive free quality content in return for personal data. This will massively increase the potential value of data assets, an area that will see much sharper publisher focus.

Development of mobile overall is affected by device fragmentation (72 per cent), in-house skills and resource (56 per cent) (see Figure 3 ). The business model for applications is showing pricing strategies diverging by device. Publishers are increasingly likely to follow paid application models on tablet (68 per cent), whereas smartphone application strategies are more likely to be split, going forward (39 per cent paid, 25 per cent free).

\section{Video becomes core editorial content}

\section{Other highlights - Video and social media}

Video is now ubiquitous, with all publishers carrying video content and a rising percentage of publishers seeing growth in consumption across all devices - desktop (94 per cent), tablet ( 72 per cent) and smartphone (63 per cent). Over 80 per cent of publishers will increase investment in video over the next 12 months, and for nine out of ten publishers, it is seen as a core editorial proposition with incremental commercial revenue benefits.

Content marketing via social media is now almost ubiquitous and likely to become more important. The key objective is increasing traffic to site (65 per cent of publishers), followed by improving SEO link building and increasing engagement with prospects and customers. 
Cookies threat reduces

\section{Battle for talent}

Social posts are considered the most effective form of content marketing (one in three publishers), ahead of email newsletters ( 31 per cent) and video ( 22 per cent), with the most commonly applied success measure (nine out of ten publishers) being improved engagement (reduced bounce rates, more time and page views on site, etc).

\section{Threats and challenges}

When it comes to threats to the industry, the economy (noted by 63 per cent of publishers) again stands as the main challenge, ahead of competitors (54 per cent). With the long-term outlook for the economy as a whole showing no signs of material improvement, it is a safe but unwanted bet we will see at the top of the agenda for the foreseeable future.

One threat that is easing is that of the 'Cookie Law', which is regarded as making less impact now that enforcement has begun and is better understood. Compared with last year's Census, 35 per cent of publishers feel it will not have an adverse impact against the 20 per cent last year. However, with tighter privacy protection for consumers, the subject of impending EU legislation, now is not the time for complacency in the industry.

Quality recruitment and development of skills continues to be at the top of the challenges for the digital publishing industry, according to eight out of ten publishers. As publishers increasingly embrace technology within their businesses, the battle for talent becomes one against the digital giants outside the traditional media marketplace.

Finally, there is still a strong view, shared by three quarters of publishers, that advertising will dominate revenue generation for some time yet. There is also a growing belief that even in an advertising-led economy, paid content models will become increasingly widespread (68 per cent of publishers), as consumers understand the value of content and the benefits of format or platform of delivery. 